\title{
ANALYSIS OF CHANGES IN BODY BALANCE FOR WOMEN WITH MULTIPLE SCLEROSIS
}

\author{
Albertas Skurvydas, Vida Janina Česnaitienė, Kazimieras Pukẻnas, Julija Andrejeva, \\ Vytautas Streckis, Dalia Mickevičienè \\ Lithuanian Sports University, Kaunas, Lithuania
}

\begin{abstract}
Background. To obtain changes in postural control the method of static posturography is usually used. The analysis of posturogram lets us determine the character of these changes, presumes that the body balance complexity, which is expressed in body coordinates of the centre of pressure variation, is less in multiple sclerosis patients than in healthy women. This study aimed at determining the effect of multiple sclerosis on changes in balance control of patients.

Methods. Twelve women with multiple sclerosis (mean age $-43.0 \pm 5.5$ years, body mass index $-24.7 \pm$ $4.2 \mathrm{~kg} / \mathrm{m}^{2}$ ) and 15 healthy women (mean age $-44.5 \pm 3.5$ years, body mass index $-25.5 \pm 2.9 \mathrm{~kg} / \mathrm{m}^{2}$ ) were included in this study. The balance of subjects was assessed applying the method of static posturography. We calculated changes in the coordinates of the centre of body pressure displacement in the lateral and anterior-posterior directions. To assess changes in the displacement of the centre of body pressure in the lateral and anterior-posterior directions two characteristics of advanced signal processing methods, i.e. sample entropy and the index of spectral power dependence on frequency were calculated.

Results and conclusion. Traditional posturogram analysis does not show statistically significant changes between women with multiple sclerosis and healthy women. The results of the study, applying advanced signal processing methods, have shown that the complexity of the centre of body pressure displacement of women with multiple sclerosis is statistically significantly smaller compared to that of the healthy women studied. This may be a prerequisite for better rehabilitation of stroke control.
\end{abstract}

Keywords: multiple sclerosis, posture control, assesement of posture.

\section{INTRODUCTION}

$\mathrm{B}$ alance impairments are common in persons with multiple sclerosis (MS), but clinical balance tests may not detect subtle deficits in adults with MS who are not yet experiencing functional limitations or disability. Karst, Venema, Roehrs, \& Tyler (2005) observed that in the early stage of MS testing patients using Berg Balance Scale (BBS) did not reveal any balance disorders, whereas the analysis of the posturogram of changes in the coordinates of the centre of body pressure (COP) showed statistically significant differences between persons with MS and age-matched healthy adults. It has been recently found that balance parameters of persons with MS, i.e. the frequency of fluctuations and the length of trajectory of COP fluctuations, are greater among age-matched healthy subjects (Chung, Remelius, Van Emmerik, \& Kent-Braun, 2008; Karst et al., 2005; Pérennou et al., 2005; Rouger, Thoumie, Cantalloube, Lamotte, 2007)

In order to study the dynamics of functions of human motor systems, the system of balance control included, methods of non-linear dynamics have been applied. It has been established that the complexity of physiological dynamic systems enables the human body to react fast to internal and 
external alterations (Hong \& Newell, 2008; Lipsitz, 1997; Slifkin \& Newell, 1999). The complexity of behaviour of physiological systems is calculated by applying the index of entropy (Cavanaugh, Mercer, Stergiou, 2007; Richmann \& Moorman, 2000; Sabatini, 2000). Thus, for example, for calculating the complexity of balance system behaviour Approximate Entropy (ApEn) is applied most frequently (Cavanaugh et al., 2007; Sabatini, 2000). The criterion of Sample Entropy (SampEn), a more precise method for calculating the complexity of dynamic system, has been proposed by Richman and Moorman (2000). For the analysis of the spectrum of signals registered by the trajectory of fluctuations in COP, the Spectral Slope index that indicates spectral power dependence on frequency has been used (Vaillancourt \& Newell, 2003). It is known that under the impact of various neurological diseases there occurs an increase in the regularity of other physiological processes in human behaviour and as a result the complexity of these systems decreases (Lambert, Archer, \& Evans, 2001). The purpose of this study was to determine changes in postural sway of patients with multiple sclerosis.

\section{METHODS}

Subjects. Twelve women with MS (mean age $43.0 \pm 5.5$ years, body mass index (BMI) $-24.7 \pm$ $4.2 \mathrm{~kg} / \mathrm{m}^{2}$ ) (group 1) and 15 healthy women (mean age $-44.5 \pm 3.5$ years, body mass index (BMI) $25.5 \pm 2.9 \mathrm{~kg} / \mathrm{m}^{2}$ ) (group 2) were included in the study. The data of the group of women subjects affected by MS are shown in Table.

The group of persons included in the study was formed taking into consideration the severity of the disease as measured by the Kurtzke Expanded Disability Status Scale (EDSS) (Kurtzke, 1983), with the values not exceeding 4.5 points. Such a form of disease does not require inpatient care since patients are able to look after themselves. The subjects were residents of Kaunas and Kaunas region. They were invited to participate in the study by "OREMUS", the community of persons affected by the disease of multiple sclerosis (MS). Diagnosis and the form of disorder were given by neurologist after carrying out magnetic resonance imaging examination. The subjects were acquainted with the objectives of the research and the protocol.

Research protocol. The balance of the subjects was assessed by the method of static posturography. Kistler force plate was used for this purpose.
Every subject stood on the force plate for $60 \mathrm{~s}$. The position of the subjects on the platform was as follows: eyes open, looking straight ahead; feet put together, arms down at the sides, palms inwards. The duration of registering the posturogram was $60 \mathrm{~s}$, sampling rate $-100 \mathrm{~Hz}$. We registered the changes in COP displacement in the lateral (COP $\mathrm{dx}$ ) and anterior-posterior (COP dy) directions. The registration of the posturogram was started when the subjects took the correct posture on the force plate. By applying traditional methods the balance of subjects was assessed as follows:

COPdx - changes in COP displacement in the lateral direction $(\mathrm{mm} / \mathrm{s})$;

COPdy - changes in COP displacement in the anterior-posterior direction $(\mathrm{mm} / \mathrm{s})$.

Assessment of the complexity of balance: The posturograms of the two groups of subjects, women patients with MS and healthy women aged 40-50 years were assessed on the basis of two advanced signal processing methods - SampEn (Richman \& Moorman, 2000) and Spectral Slope (Vaillancourt \& Newell, 2003).

SampEn was calculated as follows:

$$
\text { SampEn }(m, r, N)=-\ln (A / B) \text {, }
$$

where $\mathrm{B}$ - total number of matches of length $\mathrm{m}$ sequences (within a tolerance $\mathrm{r}$ ) in length $\mathrm{N}$ line; A - total number of matches of length $m+1$ sequences (within a tolerance $\mathrm{r}$ ) in length $\mathrm{N}$ line; A/B stands for conditional probability that two sequences, similar within a tolerance $r$ in segment $\mathrm{m}$, will remain similar within a tolerance $r$ in segment $m+1$ too; sample entropy indicates the regularity of time series:

when SampEn $\rightarrow 0$, the process is regular;

when SampEn $\geq 2$, the process is stochastic;

Spectral Slope indicates the dependence of power spectral density on frequency and it is calculated according to the equation (Vallancourt \& Newell, 2003):

$$
\mathrm{S}=\mathrm{a}^{*} \mathrm{f}^{\mathrm{b}}
$$

where $\mathrm{S}$ - power spectral density, $\mathrm{f}$ - frequency, $\mathrm{b}$ - coefficient that indicates the dependence of power spectral density on frequency and a represents the intercept of the equation. To calculate the coefficient the following equation is used:

$$
\ln (\mathrm{S})=\ln (\mathrm{a})+\mathrm{b} * \ln (\mathrm{f}) \text {. }
$$

Spectral Slope values smaller in absolute quantity reflect the properties of the signal studied and the importance of higher frequencies. When 
Spectral Slope values are greater in absolute quantity they reflect the concentration of frequencies of the signal studied in the spectrum of lower frequencies.

Statistical analysis. SampEn and Spectral Slope results of the two groups of subjects, i.e. women patients with MS and healthy women, were compared. For comparison of these parameters in respect to group factor (healthy vs. MS) the method of analysis of variance (ANOVA) was used. The level of significance was set at 0.05 .

Statistical significance of results obtained was calculated on the basic of three criteria:

- $p$ indicates statistical significance of the difference between the means compared;

- partial eta square $\left(\eta^{2}\right)$ indicates effect size of group factor on the parameter estimated or more precisely - partial eta-square is the percent of total variance in the dependent variable accounted for by the variance between categories formed by the independent variable;

- observed power shows the power level for the effect (as usual, $\geq .80$ is considered acceptable to have confidence that one has not made a Type II error when accepting a null significance finding for the effect).

\section{RESULTS}

The overall severity as measured by EDSS scale was 3.6 points (Table). No significant difference in COP fluctuations between healthy subjects and persons with MS was found (Figure 1).

The results of the research showed SampEn of COP dy fluctuations in group 1 to be statistically significantly $\left(p=.008, \eta^{2}=.277\right.$, observed power $=$.792) smaller compared to the respective SampEn in group 2 (Figure 2), whereas there was no significant difference in SampEn of COP $d x$ fluctuations between groups 1 and 2. A smaller SampEn indicates that the complexity of COP dy fluctuations decreases, i.e. fluctuations tend to become more regular (less complex).

The data of spectral analysis showed that the Spectral Slope of COP in the anterior-posterior direction (COPdy) in group 1 was statistically significantly $\left(p=.014, \eta^{2}=.233\right.$, statistical power $=.717)$ higher than the respective Spectral Slope (COP dy) found in group 2 (Figure 3). No significant difference in the Spectral Slope of COP $\mathrm{dx}$ fluctuations between groups 1 and 2 was found.

Spectral Slope absolute mean values of women patients with MS were greater and that shows fluctuations in the case of persons with MS to be concentrated rather in the range of low frequencies.
Table. Data of women with multiple sclerosis

Notes. BMI - body mass index; EDSS Kurtzke Expanded Disability Status Scale.

\begin{tabular}{|c|c|c|c|l|c|c|c|c|}
\hline No & Age & $\begin{array}{c}\text { Year of } \\
\text { diagnosing } \\
\text { MS }\end{array}$ & $\begin{array}{c}\text { Duration } \\
\text { of disease }\end{array}$ & $\begin{array}{c}\text { Form of } \\
\text { disease }\end{array}$ & $\begin{array}{c}\text { Height } \\
(\mathbf{c m})\end{array}$ & $\begin{array}{c}\text { Weight } \\
\mathbf{( k g})\end{array}$ & BMI & EDSS \\
\hline 1. & 46.3 & 1996 & 12 & $\begin{array}{l}\text { Secondary in } \\
\text { progress }\end{array}$ & 164 & 69.4 & 25.8 & 4.5 \\
\hline 2. & 43.4 & 1998 & 10 & $\begin{array}{l}\text { Secondary in } \\
\text { progress }\end{array}$ & 172 & 89 & 30.1 & 4.5 \\
\hline 3. & 54.1 & 1999 & 9 & $\begin{array}{l}\text { Secondary in } \\
\text { progress }\end{array}$ & 165 & 54.6 & 20.1 & 3.5 \\
\hline 4. & 37.8 & 1998 & 10 & $\begin{array}{l}\text { Secondary in } \\
\text { progress }\end{array}$ & 169 & 64.8 & 22.7 & 4 \\
\hline 5. & 43.5 & 2004 & 4 & $\begin{array}{l}\text { Secondary in } \\
\text { progress }\end{array}$ & 173 & 76.1 & 25.4 & 4.5 \\
\hline 6. & 46.4 & 2002 & 6 & $\begin{array}{l}\text { Secondary in } \\
\text { progress }\end{array}$ & 162 & 67.4 & 25.7 & 3.5 \\
\hline 7. & 39.5 & 2001 & 7 & $\begin{array}{l}\text { Secondary in } \\
\text { progress }\end{array}$ & 178 & 61.2 & 19.3 & 3 \\
\hline 8. & 43.9 & 2000 & 8 & $\begin{array}{l}\text { Secondary in } \\
\text { progress }\end{array}$ & 172 & 89 & 30.1 & 3.5 \\
\hline 9. & 33.2 & 1999 & 9 & $\begin{array}{l}\text { Secondary in } \\
\text { progress }\end{array}$ & 171 & 61.2 & 20.9 & 3 \\
\hline 10. & 46.3 & 2000 & 8 & $\begin{array}{l}\text { Secondary in } \\
\text { progress }\end{array}$ & 174 & 66.9 & 22.1 & 3 \\
\hline 11. & 44.8 & 1999 & 9 & $\begin{array}{l}\text { Secondary in } \\
\text { progress }\end{array}$ & 186 & 76.1 & 22 & 3.5 \\
\hline 12. & 37.0 & 2001 & 7 & $\begin{array}{l}\text { Secondary in } \\
\text { progress }\end{array}$ & 175 & 98.1 & 32 & 3 \\
\hline
\end{tabular}




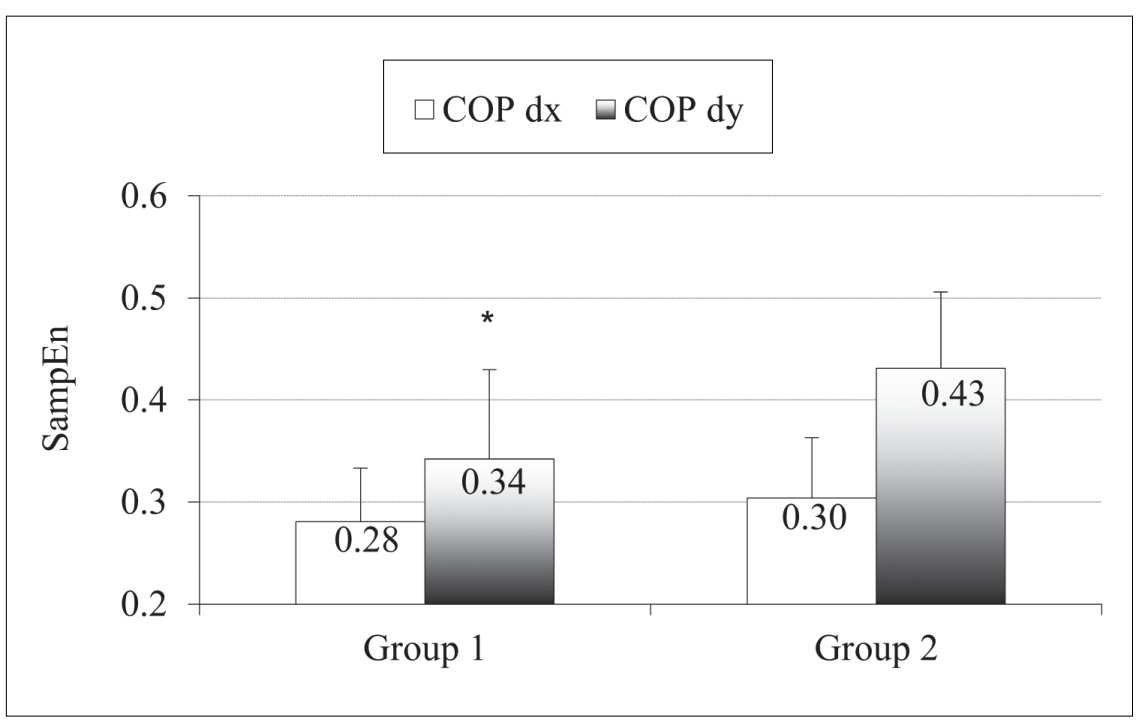

Figure 1. Mean values $(\mathrm{mm} / \mathrm{s})$ of changes in $\mathrm{COP}$ in the lateral (COP dx) and anterior-posterior (COP dy) directions

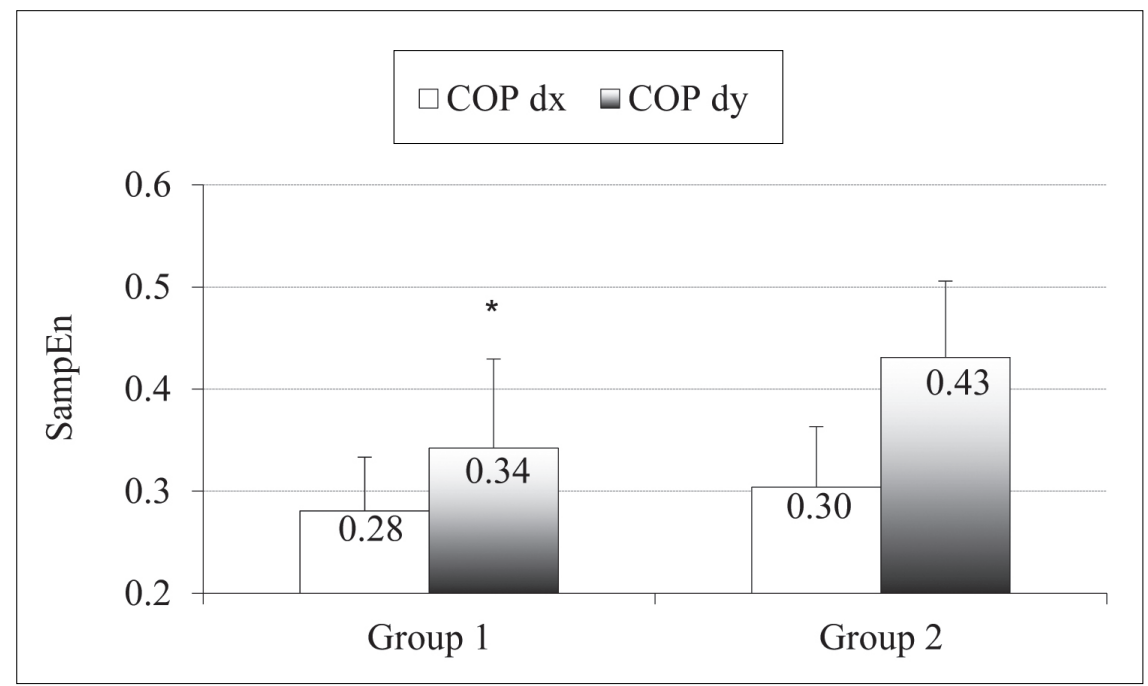

Figure 2. Mean values of Sample Entropy (SampEn)

Note. ${ }^{*}-p<.01$, group 1 compared to group 2.

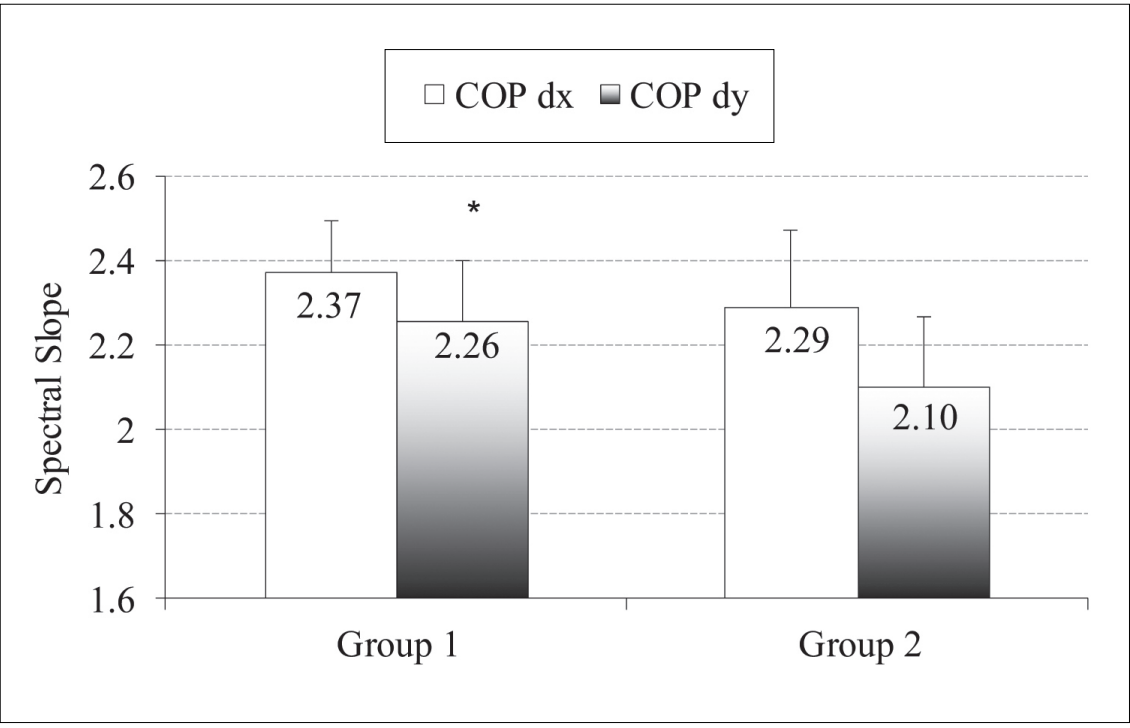

Figure 3. Mean values of Power Spectral Density dependence on Spectral Slope

Note. ${ }^{*}-\mathrm{p}<.05$, group 1 compared to group 2. 


\section{DISCUSSION}

The results of this study have shown that there were no statistically significant differences in the rate of changes in the coordinates of COP both in the lateral and anterior-posterior directions between women patients with MS and the controls. This contradicts to the conclusions of other researchers who maintain that in case of MS the rate of changes in the coordinates of $\mathrm{COP}$ and its trajectory increases (Chung et al., 2008; Karst et al., 2005; Perennou et al., 2005; Rouger et al., 2007). We have established that in patients with MS the signals of COPdy fluctuations are more concentrated in the range of low frequencies. It could be assumed that with low fluctuation frequencies prevailing, the system of balance control becomes slower.

We have found the complexity of balance system behavior (SampEn) of women with MS to be statistically significantly smaller compared to that of the healthy women studied. This is in accord with the data of other researchers who consider the complexity of the unhealthy physiological system to be smaller than that of the healthy one (Lipsitz \& Goldberger, 1992). Multiple sclerosis is a disease of CNS characterized by demyelization of the nervous neural pathways and derangement of nervous impulses from CNS (Deuschl, Bainm, \& Brin, 1998). The exacerbation of the disease gives rise to multifarious foci of demyelization. Some axons are therefore no longer remyelinized and start dying out. Due to disintegration of the myelin sheath in the cases of exacerbation of the disease patients with MS fail to activate the muscle and to effectively control it (Lambert et al., 2001). This is the main reason why the complexity of balance maintenance of patients with MS is poorer than that of healthy persons. In other words, in conditions of MS disease motor control slows down. Then the brain fails to plastically adapt itself to the various conditions of movement performance. Consequently, this failure in adaptation decreases the complexity of balance control. With a decrease in the complexity of balance control, the control of balance system becomes more vulnerable. This does not rule out balance disorders that will have a negative effect on the functional condition of patients with MS. Balance control impairment in persons with multiple sclerosis (MS) is one of the main reasons decreasing the functional capacity of the patient.

Our results have shown that while registering the posturogram at the frequency of $100 \mathrm{~Hz}$, it is difficult to detect displacement of the centre of pressure in the linear measurements affected by changes in the disease. The study by Huisingaa, Yentesa, Filipi, \& Stergioua (2012) showed that for patients with multiple sclerosis at a very early stage of disease, changes in the trajectory of the centre of pressure and the velocity of sway were observed compared to healthy subjects. Inconsistencies in the results of these two studies can be explained by different research conditions. We believe that the registration of posturogram for 5 minutes leads to changes in balance control due to fatigue, which significantly increases the length of the path and the velocity of sway of the centre of pressure. Recording posturogram for 60 seconds was sufficient time to fully register changes in balance behaviour for patients with multiple sclerosis and healthy controls using nonparametric methods.

The results of the study, applying advanced signal processing methods, have shown that the complexity of the centre of body pressure displacement of women with multiple sclerosis is statistically significantly smaller compared to that of the healthy women studied. The balance system of patients with multiple sclerosis is less complex than that of healthy adults of the same age and it confirms the optimal movement variability hypothesis.

\section{REFERENCES}

Cavanaugh, J. T., Mercer, V. S., \& Stergiou, N. (2007). Approximate entropy detects the effect a secondary cognitive task on postural control in healthy young adults: A methodological report. Journal of NeuroEngineering and Rehabilitation, 42, 1-7.

Chung, L. H., Remelius, J. G., Van Emmerik, R. E., \& Kent-Braun, J. A. (2008). Leg power asymmetry and postural control in women with multiple sclerosis.
Medicine \& Science in Sports \& Exercise, 40(10), 17171724.

Deuschl, G., Bainm P., \& Brin, M. (1998). Consensus statement of the movement disorder society on tremor. Movement Disorders, 13 (Suppl. 3), 2-23.

Hong, S. L., \& Newell, K. M. (2008). Entropy compensation in human motor adaptation. Chaos, 18(1), 103-108. 
Huisingaa, J. M., Yentesa, J. M., Filipi, M. L, \& Stergioua, N. (2012). Postural control strategy during standing is altered in patients with multiple sclerosis. Neuroscience Letters, 524, 124-128. doi:10.1016/j. neulet.2012.07.020

Karst, G. M., Venema, D. M., Roehrs, T. G., \& Tyler, A. E. (2005). Centre of pressure measures during standing tasks in minimally impaired persons with multiple sclerosis. Journal of Neurologic Physical Therapy, 29(4), 170-180.

Kurtzke, J. F. (1983). Rating neurologic impairment in multiple sclerosis: An expanded disability status scale (EDSS). Neurology, 33(11), 1444-1452.

Lambert, C., Archer, R., \& Evans, W. (2001). Muscle strength and fatigue during isokinetic exercise in individuals with multiple sclerosis. Medicine \& Science in Sports \& Exercise, 33(10), 1613-1619.

Lipsitz, L. A. (1997). Physiological complexity, aging and the path to frailty. Science of Aging Knowledge Environment, 97, 454-455.

Pérennou, D., Decavel, P., Manckoundia, P., Penven, Y., Mourey, F., \& Launay, F. (2005). Évaluation de l'équilibre en pathologie neurologique et gériatrique (Evaluation of balance in neurologic and geriatric disorders). Annales Readaptation et de Medecine Physique, 48(6), 317-335.

Richmann, J. S., \& Moorman, J. R. (2000). Physiological time series analysis using approximate entropy and sample entropy. American Journal of Physiology-Heart and Circulatory Physiology, 278, 2039-2049.

Rouger, P., Thoumie, P., Cantalloube, S., \& Lamotte, D. (2007). Quelles stratégies motrices de compensation les patients souffrant d'une sclérose en plaques sont-ils capables de développer pour contrôler leur équilibre? (What compensatory motor strategies do patients with multiple sclerosis develop for balance control?) Annales Readaptation et de Medecine Physique, 163(11), 10541064.

Sabatini, A. M. (2000). Analysis of postural sway using entropy measures of signal complexity. Medical \& Biological Engineering \& Computing, 38, 617-624.

Slifkin, A. B., \& Newell, K. M. (1999). Noise, information transmission, and force variability. Journal of Experimental Psychology: Human Perception and Performance, 25(3), 837-851.

Vaillancourt, D. E., \& Newell, K. M. (2003). Aging and the time and frequency structure of force output variability. Journal of Applied Physiology, 94, 903-912. 